\title{
26 Research Square \\ Establish a teleost skin explant model for studying the fish-pathogen interaction
}

\author{
Ru-Fang Siao \\ National Sun Yat-sen University \\ Chia-Hsuan Lin \\ National Sun Yat-sen University \\ Liang-Chun Wang ( $\square$ marknjoy@g-mail.nsysu.edu.tw ) \\ National Sun Yat-sen University
}

\section{Research Article}

Keywords: teleost, fish skin, pathogenesis

Posted Date: February 17th, 2021

DOl: https://doi.org/10.21203/rs.3.rs-204750/v1

License: (c) (1) This work is licensed under a Creative Commons Attribution 4.0 International License. Read Full License 


\section{Abstract}

Teleost fish skin serves as the first line of defense against pathogens. The interaction between pathogen and host skin determines the infection outcome. However, the interaction and infection mechanisms remain largely unknown due to the lack of a proper tissue model that can quantitatively and qualitatively monitor infection progress. Here, we use striped catfish (Pangasius hypophthalmus) to establish an ex vivo skin explant tissue model that has not been explored in teleost fish before. The skin explant model, cultured by creating epithelial polarity, resembles the in vivo skin in tissue morphology, integrity, and mucous cell and immune functionality. Inoculation of Aeromonas hydrophila in this model induces epidermal exfoliation along with epithelial cell junction disassembly and inflammation. We therefore concluded that this ex vivo skin explant model could serve as a teleost skin infection model for monitoring pathogenesis under various infection conditions. The model can also potentially be translated into a platform to study prevention and treatment for aquatic infection on mucosal surface in aquaculture applications.

\section{Introduction}

Fish skin is an exquisite first line of barrier responding to environmental change, including aquatic pathogens ${ }^{1}$. The mucous layer coated on the skin serves as additional protection against pathogens. Scaleless fish produce explicitly higher levels of mucous than scaled fish ${ }^{2,3}$. Thus, the protective barrier function of mucosal skin is more important in scaleless fish than in scaled fish. The skin of scaleless teleost fish, such as catfish and eels of economic importance, is mainly composed of the epidermis and dermis. The epidermis is the outermost region and ranges from two to multiple epithelial cell layers, determined by species, age, and anatomical location ${ }^{4}$. The epidermis contains various quantities and types of epithelial cells, mainly including stratified and mucous epithelial cells. The underlying dermis composes fibroblast cells that secret collagens, making up the soft connective tissue layer. When encountering pathogens, the skin can respond in several ways. The epithelial cells can secret mucous and antimicrobials to kill the pathogens. The cytokine production can signal and attract neutrophils, mast cells, and macrophages for pathogen clearance ${ }^{5}$. The mucous has been shown to avoid pathogen attachment and kept the antimicrobials secreted from the host ${ }^{6}$. The antimicrobial secretion such as antimicrobial peptides, lectins, lysozymes, and proteases from epithelial cells located in the fish epidermis has been shown to kill pathogens by various mechanisms ${ }^{7}$. The cytokine response, relying on a signal transduction pathway from the pathogen recognition receptors such as Toll-like receptors (TLRs) to the cytokines such as Interleukins (ILs) and Tumor necrosis factors (TNFs), plays an essential role in pathogen clearance as part of the innate immune response $e^{8,9}$. These secretions, along with cells from the epidermis, are essential for responding to pathogen invasion. Nevertheless, less information is explored on the mechanism of how pathogens initiate and progress these responses on host skin.

Current studies of the interaction mechanism rely on observing the in vivo fish ${ }^{10}$ or the cell line based single epithelial or immune cell model system ${ }^{11}$. The majority of teleost fish-pathogen interaction studies 
use the in vivo fish to observe the survival rate, physiological change, and the presence of pathogenic bacteria in specific organs or tissues to deduce infection routes and mechanisms. However, the in vivo model has its limitations in detailing the progression of the infection. First, the host gene expression can be different in each experimental individual. A study of rainbow trout has shown the difference in protein synthesis and turnover between the same breed ${ }^{12}$. A mice study has also demonstrated that the gene expression in kidneys, testis, and livers can significantly differ within the same $\operatorname{strain}^{13}$. Second, the difference exists in the associated microbiome from fish to fish. The microbiome is defined as the microbial community with distinct physio-chemical properties ${ }^{14}$. The same mice model can have a different gut microbiome, impacting the result interpretation and reproducibility ${ }^{15}$. Lastly, the teleost infection in vivo undergoes a complicated process containing interactions among the environment, pathogens, host, and its microbiome. Using in vivo model to detail the infection mechanism may overlook the process leading to an ambiguous conclusion ${ }^{16}$. Besides, the amount of fish sacrificed for data validity can be enormous. Therefore, an alternative model should be considered.

Primary and cell-line based epithelial or immune cells were considered alternative models for studying fish skin infection because of their simple, stable, and easy-to-handle properties. However, using the epithelium cells or immune cells alone to study mechanisms is a double-edged sword due to the narrow interpretation from single-cell culture. Despite the convenience of manipulation, it has been generally recognized that single-cell culture does not reflect the in vivo cellular processes due to the lack of multicellular interaction ${ }^{17}$. Nevertheless, teleost fish cell line or primary cell culture is still the only choice besides in vivo teleost fish. To date, there are many cell lines established commercially and have been widely used. Among these establishments, the gill cell lines are the most widely used. Even though epithelial polarity was not explored, the cultured RTgill-W1 and G1B cell line on a semipermeable insert form a multilayered epithelium for the parasite infection study ${ }^{18}$. The primary cell culture was also considered more representative than the cell line due to their homogeneity similarity to their hosts. The primary fish gill system has then been established for aquatic environmental monitoring ${ }^{19}$. Nonetheless, in both cell line and primary cell culture, the gene expression and protein function can also significantly differ from in vivo models due to the lack of multiple cell type signaling. The mice model has proven the difference though it has not been intensively examined in teleost fish ${ }^{20}$. As a result, a novel model sitting in between in vitro single cell type and in vivo fish with all the skin cell variety presented and integrated is needed. The closest study of the everted intestinal sac using the whole intestine was used to study substance absorption in teleost fish ${ }^{21}$. Another study examining tissue repair used the whole fish scale as epidermal sheets to study tissue repair ${ }^{22}$. While claiming tissue integrity, cell organization, and cellular responses similar to the in vivo fish, the limited experiment sets from only one fish can discourage using the model. Besides, the fish skin model needs to have epithelial polarity for genuinely mimicking osmoregulation and barrier function of the skin. A previous study showed that an ex vivo human peritoneal tissue model, by independently culturing internal and external surfaces, can be established with epithelium polarity for exploring tumor-peritoneal interaction ${ }^{23}$. A recent study has also used toad skin explant to successfully monitor viral infection from external to the internal surface of the $\operatorname{skin}^{24}$. 
Nonetheless, a similar study in teleost fish skin hasn't been explored. Therefore, developing an ex vivo skin model system comparable to the models above can potentially mimic fish mucosal skin and serve as a model for infection research.

This study aimed to establish an ex vivo mucosal skin model for studying teleost fish infection. The model, away from the current in vitro model, can mimic in vivo fish skin tissue by presenting all skin properties, including epidermis with epithelial cells and dermis with the dense connective. Due to its organ-based property, it is practically suitable for infection study as well as physiological study. Several skin models can be processed from a single fish, thus, reducing experimental error from individual genetic differences. Moreover, the need for labor, space, feeds can be significantly reduced due to the decreased number of fish used in experiments. Eventually, this model can serve as a multi-purpose platform for fish mucosal surface research and an alternative or additive approach besides in vivo fish.

\section{Results}

The P. hypophthalmus skin model preserves tissue morphology and integrity

To examine if the skin tissue integrity was maintained in the skin model, tissue sections of fresh skin, cultured skin, and skin model of the dorsal or ventral region were stained with Giemsa solution. The tissue morphology and integrity of the skin were then examined by light microscopy (Fig. 1A). We found the skin model, but not cultured skin, resembles fresh skin in both regions. The skin model and fresh skin of the ventral region showed a bottom layer of basal epithelial cells (BC) and superficial epithelial cells (SC) with club cells (CC) in between, whereas cultured skin only expressed a thin layer of basal epithelial cells. To further determine if the epidermis layers were sustained during preparing the model, the epidermal thickness of fresh skin, cultured skin, and skin model was measured and compared (Fig. 1B). We found that the thickness of the skin model remained unchanged while the cultured skin was $65 \%$ decreased in dorsal and $74 \%$ decreased in ventral compared to fresh skin. The transepithelial electrical resistance (TEER) is the measurement of electrical resistance across the epithelial layer and can be applied to quantify the barrier integrity during their stages of growth ${ }^{25}$. We used this measurement to examine the integrity of the epithelial layer in the skin model and monitored for consecutive 18 days (Fig. 1C). The TEER of the fish skin model showed a significant increase from day 1 to day 5 at the maximum of $2158 \Omega / \mathrm{cm}^{2}$ in dorsal and $2034 \Omega / \mathrm{cm}^{2}$ in ventral on day 5 and were maintained till day 18 . These data have shown that the overall tissue morphology and cell integrity of the dorsal or ventral skin model resembled the fresh skin.

\section{Tight junctions are expressed and distributed in the epidermis of the skin model similarly to fresh skin}

Previous studies have shown that tight junction, as part of epithelial intercellular adhesion complex, plays an essential role in the teleost fish skin barrier function and osmolality regulation ${ }^{26}$. Claudin- 1 is one of the most studied and major epidermal tight junction proteins in teleost fish ${ }^{27}$. Lack or changes in the distribution of Claudin-1 can lead to increases in the epidermal paracellular permeability ${ }^{28}$, resulting in 
vulnerability to environmental pathogens ${ }^{29}$. We sought to examine the junction integrity in our skin model by investigating the distribution and expression level of Claudin-1. To examine the distribution of Claudin1 in skin model, skin model, fresh skin, and cultured skin were stained with anti-Claudin-1 antibody and imaged by fluorescence microscopy (Fig. 2A). We found Claudin-1 was distributed on the peripheral of the epithelial cell and epithelial cell-club-cell contact in the epidermis of skin model similar to the fresh skin while only on the top of a single epithelial layer in cultured skin. No noticeable difference was observed in Claudin-1 distribution comparing the ventral and dorsal regions in the skin model. To determine if the skin model maintains the same expression level of junction proteins, the expression levels of tight junction components, including Claudin-1, Occludin-1, and ZO-1, were examined using RTqPCR (Fig. 2B). In dorsal regions, the expression level of Claudin-1, Occludin-1, and ZO-1 were not significantly altered in cultured fish skin and the skin model compared to fresh skin. In the ventral region, the expression of Claudin-1 in the skin model had a 3-fold increase than cultured skin, while little alteration of Claudin-1, Occludin-1, and ZO-1 was observed compared to fresh skin. These data suggest the function and distribution of the apical junctions in the skin model resembles the fresh skin; therefore, the skin model exerts comparable skin barrier function.

\section{The skin model preserves the distribution and function of mucous cells to the extent of fresh skin}

Fish skin mucous and various antimicrobial secretion acts as another layer of barrier against pathogens besides skin $^{30}$. The main component, gel-forming mucous, is secreted mainly by mucous goblet cell $(M G C)^{31}$. The maintenance of MGC number and mucous secretion indicate the status of healthy skin. We hypothesized that the MGC number and secretion were maintained in the skin model based on the observation of overall tissue and junction integrity. To determine if the skin model can preserve MGCs distribution within the epidermis similar to the fresh skin, the skin model was stained with Alcian bluehematoxylin stain, imaged, and quantified for subsequent morphometric analysis. In both dorsal and ventral regions, the MGCs were distributed on the outmost layer of epithelial cells and in the epidermis in both skin model and fresh skin, while sporadic MGCs were distributed on the single layer of the epidermis in cultured skin (Fig. 3A). In both dorsal and ventral skin, the number and size of MGCs in the skin model resembled fresh skin, whereas a significant decrease in both metrics found in cultured skin (Fig. 3B and 3C). We then investigated the activity of MGCs by examining the expression level of MUC5AC, a gene for mucous that is responsible for gel-forming mucous secretion (Fig. 3D). In the dorsal region, $55 \%$ and $88 \%$ expression decrease in MUC5AC was observed in the skin model and cultured skin compared to fresh skin. In the ventral region, no significant change was observed between the skin model and fresh skin ( $P$ $=0.336$ ) but a $60 \%$ expression decrease in the cultured skin. These data suggested that the mucous cell of the skin model is preserved in number and function and can represent fresh skin fully in the ventral and partially in the dorsal region.

\section{Fish skin model expresses different levels of innate immune factors compared with fresh skin}


The active innate immune system in teleost skin plays an essential role in responding to pathogen surface molecules and inducing inflammatory responses ${ }^{16}$. To investigate if this active immune system was preserved in our skin model, we measured the expression level of surface pathogen recognition receptors TLR4 and TLR5, the intracellular signal transduction molecule NF-KB, and inflammatory cytokines IL-1 $\beta$ and TNF- $\alpha$ using RT-qPCR in dorsal and ventral region and compared to fresh skin as well as cultured skin (Fig. 4). In both dorsal and ventral regions, we found a 2-5-fold decrease of TLR4 and TLR5 in the skin model and cultured skin compared to fresh skin (Fig. 4A and 4B). Similarly, a decrease of more than two folds in IL-1 $\beta$ and TNF- $a$ was observed comparing fish skin and cultured skin to fresh skin (Fig. 4C and 4D). On the other hand, we did not find a significant change in NF-KB (Fig. 4E). These data suggested the skin model exerts a lower level of expression in the active immune system.

\section{AH induces redistribution of Claudin-1 and elicited epidermal cell exfoliation in the skin model}

Previous studies have shown that the ventral region of scaleless fish is more susceptible to pathogen infection due to mucous-rich contents that can harbor pathogens ${ }^{32}$. The pathogens can then adhere to the skin and induce hemorrhage in catfish ${ }^{33}$. We then used the ventral skin model to validate the establishment of the infection model. To establish an infection model, we inoculated Aeromonas hydrophila (AH), a common freshwater pathogen, into the apical side of the ventral skin model for $6 \mathrm{~h}$ and investigated tissue integrity and the barrier function compared to no bacteria control. To test whether the tissue integrity changes on AH inoculated skin model, we examined Claudin-1 distribution by immunofluorescence staining and fluorescent microscopy (Fig. 5A). We found Claudin-1 was redistributed and become dotted peripherally or intracellularly in surface epithelial cells in AH inoculated skin model compared to control. We also found the Claudin-1 disappeared or weakened surrounding the club cells and on the top of basal epithelial cells in the AH inoculated skin model. To further test if the change of Claudin-1 protein expression can exhibit barrier loss and tissue integrity, we measured the TEER of the inoculated skin model and quantified the exfoliated cell number in the apical side compare to no bacteria control. A significant 30\% decrease in TEER (Fig. 5B) and 10-fold increase in the exfoliated cell number (Fig. 5C) were observed in AH inoculated skin model compared to the no bacteria control. The results demonstrated that inoculation of $\mathrm{AH}$ could induce tissue disintegration from disruption and endocytosis of tight junction in the skin model.

\section{The expression of innate immune markers is stimulated in the $\mathrm{AH}$ inoculated skin model}

The chained innate immune response from pathogen recognition to cytokine or antimicrobial secretion is the critical route to fight against infection ${ }^{34}$. To test if $\mathrm{AH}$ inoculation can elicit these responses, the expression of immune markers previously mentioned as well as mucous in $\mathrm{AH}$ inoculated ventral skin model was measured by RT-qPCR. We found that all of the markers had significantly increased in AH inoculated model compared to the control. The expression of TLR4 and TLR5 had a 2.3 and 2.7-fold 
increase respectively (Fig. 6A and 6B). The expression of NF-kB had a 5-fold increase (Fig. 6C). The expression of two downstream pro-inflammatory cytokines, IL-1 $\beta$ and TNF-a, had a 3.3-fold and 5.7-fold increase respectively (Fig. 6D and 6E). MUC5AC expression had a 3.6-fold increase (Fig. 6F). These data strongly suggested that innate immune response can be induced by AH inoculation in the skin model even though the basal level expression is lower than the fresh skin in previous results.

\section{Discussion}

Little is known about pathogenesis on teleost skin infection due to the lack of a proper model as stable as in vitro cell line yet as complicated and integrated as in vivo tissue or organ. This study established a tissue-based ex vivo teleost skin model that has not been explored before for studying skin infection. The skin model was made of the teleost dorsal or ventral skin shows overall epidermal and connective tissue integrity with epithelial growth. The continuous structure of apical junction and the expression and secretion of mucous resembles skin epidermis in vivo. Taking advantage of the slight amount of skin needed for the model, several sets of experimental conditions can be tested with a single fish, reducing the total animal sacrifice yet eliminating the genetic difference between each fish. While the basal level of innate immune expression is relatively low compared to in vivo skin, elevated epithelial and immune responses to the pathogenic bacterium $\mathrm{AH}$ are observed and comparable to other in vivo studies. Overall, this skin model resembles in vivo teleost skin with or without infection. Thus, it can serve as an alternative of the in vivo model and potentially detail the pathogenesis of teleost related infection.

Epithelial polarity formation is critical for developing fully functional mucosal surfaces. Studies have shown that separating apical and basal environments is necessary for the epithelial cell to form intercellular junctions leading to polarity ${ }^{35}$. Therefore, a skin model with polarized epithelial cells can be developed considering creating distinct internal and external sides. In RTgill-W1 cells cultured under transwell system has been shown to generate the polarity compared to non transwell system ${ }^{36}$. The mucosal skin model of many species has been made based on the concept of the transwell system. In teleost fish, efforts towards polarizing epithelial have also been made. The previous study showed that the double seeded transwell system of gill epithelial cells exerts higher polarity and lower permeability than the single-seeded transwell system ${ }^{37}$. Our model, established with the same concept by separating the culturing environment into the apical and basal side, has shown the properties of polarity, including growing transepithelial resistance, apical junction marker, and epidermal integrity contrast to the cultured mucosal skin without separating two environments showed significant loss of upper epithelial and club cells and insufficient apical junction formation on basal layer. Nonetheless, we noticed the junction marker Claudin-1 on the skin model redistributed gradually from day 10 to 15 (Supplementary Fig. S1). In the dorsal and ventral region of the skin model, Claudin-1 was redistributed to the outer layer of superficial epithelial cells (SC). Two possible explanations for that can be discussed - the loss of environmental cues and the lack of proper growth factors. Studies have proved that polarization can be achieved by giving different environment cues on each side ${ }^{38}$. Berube et al. found the lack of serum or hydration of the apical side polarizes human airway epithelial cells ${ }^{39}$. Dao Thi et al. found that 
successful hepatocyte polarization from stem cells can be achieved by taking serum out from one side of the transwell system ${ }^{40}$. Both studies suggested the environmental cue is essential with feeding serum to the basal side only. The lack of proper growth factor can also change basal cell development. The dermis of fish skin is rich in the extracellular matrix (ECM), connecting epithelial cells to the underlying dermis. Studies have shown that epidermal growth factor can stimulate ECM secretion and promote skin epidermal cell proliferation ${ }^{41,42}$. Basolaterally change of serum-free media and fish-specific hormone, such as epidermal growth factor and transforming growth factor ${ }^{43}$, may continuously stimulate the basal cell development and organization in the long-term culturing.

The existence of mucous cells and mucous secretion has long been an indication of fully developed mucosal surfaces. In scaleless fish, such as catfish, mucous is often emphasized in defending pathogens and responding to surrounding chemical alteration ${ }^{31}$. Thus, numerous morphometric studies have detailed the distribution and quantity of mucous cells in a different genus of catfish ${ }^{44,45}$. Very few studies have conclusive findings on the number and the distribution of mucous cells in P. hypophthalmus. Our findings have shown that the distribution and quantity of MGC in both fresh skin and model were similar. The mucous expression of the model is similar in both fresh skin and the skin model. Consistent with the data, mucous secreted from MGC were observed in both fresh skin and the skin model located at the superficial epithelial cell surface (Supplementary Fig. S2). The images indicate the integrity and functionality of a fully grown skin mucosal epithelia. Nonetheless, club cells, which is the second most distributed cell type in the epidermis, have also been suggested to contain and potentially secret proteinaceous mucous ${ }^{46,47}$. Two types of mucous-secreting cells are shown here, potentially secreting a mixture of mucous. It would be interesting to examine the composition of the secreted mucous in our model and to compare the physiological existence of certain glycosylated or un-glycosylated mucous with fresh skin.

The expression of immune markers is an indicator of the immune response to various pathogenic bacteria infection. The established cytokine secretion pathway from surface TLRs down to ILs is often used to validate the established pathogen defense pathways ${ }^{48}$. Interestingly in our model, we noticed a deceased expression of TLRs and ILs but not NF-KB compared to fresh skin. We reason that the lack of mucosal microbiome may be the leading cause of decreased expression level. Lots of studies found the immunostimulant function of fish mucosal microbiome ${ }^{49,50}$. Also, similar evidence showed the gnotobiotic zebrafish, with the absence of microbiome, has reduced immune gene expression compared to the one exposed to microbiome ${ }^{51}$. The lack of microbiome may explain the low immune activation in our skin model cultured in media with antibiotics. The absence of the microbiome can represent the gnotobiotic fish skin where immunostimulation is lacking. However, the microbiome can also serve as a buffer to reduce skin mucosal immune overexpression and maintain stability when encountering the pathogen ${ }^{52,53}$. Li et al. showed that, even with partial mucous removal, the innate immune marker expression maintains the same level during 2-12 $\mathrm{h}$ infection of $\mathrm{AH}$ using the blue catfish ${ }^{54}$. This implies an immune-suppression role of the mucous microbiome in fish infection, which explains the immediate upregulation of TLR4 and TLR5 along with IL-1 $\beta$ and TNF- $\alpha$ in our skin model inoculated with the low 
number of $\mathrm{AH}$. The loss of mucosal microbiome may contribute to the decreased buffering and, therefore, a robust immune response to infections. The microbiome potentially plays a role in modulating skin immune response. It would be interesting to address the role of the mucous microbiome using our model.

Although the skin model can resemble the in vivo innate immune functionality of skin epithelial in our experiment system without the microbiome, there are still limitations to consider. One limitation is the reduction of in vivo level of immune cells and their activation. In general, epithelial cells of stressed fish can release cytokines to activate and direct immunocytes to the targeted tissue ${ }^{55}$. High numbers of activated macrophages in the skin and increased T cell activation were then responsible for pathogen recognition and eventually clearance ${ }^{56}$. In our skin model, however, immunocytes are not expected to be retained after long-term culture. Another limitation is the fish endocrine system response. Maintenance of fish skin homeostasis relies on the interaction between immune and endocrine balance. Brian et al. show that cortisol released by the fish gland endocrine system could suppress the inflammation to protect tissues from cytotoxic damage ${ }^{57}$, while Pagniello et al. indicated cortisol induced the proliferation of macrophages in rainbow trout cell line ${ }^{58}$. Therefore, it would be interesting to examine the interplay of immunocytes and cortisol in the skin model to study the defense mechanisms.

Our teleost skin model is demonstrated to resemble in vivo fresh skin with more tissue morphology and characteristics preserved. The whole tissue without chemical or physical modification and damage has been proven and used to mimic in vivo organ or tissue in a physiologically identical manner. In humans, a 3D skin ex vivo model made from biopsies has been developed in the same manner and used for investigating anaerobic bacterial infection and the host immune response under the skin ${ }^{59}$. Another study developed an ex vivo human peritoneal tissue model to explore mesh-tissue integration using the explants $^{23}$. In these investigations, the model was built up and can be maintained for three weeks, ideal for applicable infectious disease observation. However, the limited epithelial renewal found in these models leaves the need for improvements to perform long-term experiments. The fish skin model system developed in this study can last for at least 20 days, serving as a model for short-term infection study or other physiological studies. A further study exploring the more extended growth and maintenance of this model is needed.

Taken together, this skin model has shown the similar epidermal property and functionality of fresh skin for weeks. The pathogen challenge can induce the activation of innate immune response responding to pathogen challenge. To our best knowledge, this explant-based ex vivo skin model has not been explored before. Thus, this model can potentially serve as a platform for studying fish skin infection and its control and prevention prospectively.

\section{Materials And Methods}

\section{Animal husbandry}


Pangasius hypophthalmus were obtained from a local aquarium vendor. All fish were housed in a $300 \mathrm{~L}$ tank at $25^{\circ} \mathrm{C}$ and held constant photoperiod ( $12 \mathrm{~h}$ light; $12 \mathrm{~h}$ dark) in the aquaculture room at the Department of Marine Biotechnology and Resources. Fish skin tissue was prepared from observationally healthy fish with an average weight of $35 \mathrm{~g}$ and ten months old. This study was carried out in compliance with the ARRIVE guidelines. All the animal experiments were approved by the Institutional Animal Care and Use Committee (I.A.C.U.C.) at National Sun Yat-sen University under protocol No. IACUC-10834.

\section{Skin tissue collection}

Fish were anaesthetized by rapid chilling followed by cervical transection. The experiment was conducted in accordance with AVMA Guidelines for the Euthanasia of Animals. The fish skin tissue was then removed from the fish by scalpel and immediately immersed into cold L-15 medium (SIGMA, U.S.A.) supplemented with $10 \%$ fetal bovine serum, $2 \%$ gentamycin solution (SIGMA, U.S.A), 1 X antibioticantimycotic (Biowest, U.S.A.).

\section{Fabrication of model}

The skin tissue was separated into the ventral and dorsal regions based on the lateral line. Dorsal skin and ventral region were collected from dorsal fin and pelvic fin to lateral line, respectively. After cutting into squares of approximately $10 \times 10 \mathrm{~mm}$, skin tissue was mounted between two plastic crowns. The tissue, along with the crown, was gently submerged in the culture medium in a 24-well culture plate. In cultured skin, the skin was submerged in the culture medium in a 24-well culture plate. The plate was cultured in a $\mathrm{CO}_{2}$-free incubator at $25^{\circ} \mathrm{C}$. The culture medium was changed every two days until further experiments. The media was replaced with non-antibiotic media $24 \mathrm{~h}$ before the infection experiment.

\section{Bacteria cultivation and infection}

Aeromonas hydrophila (AH) was purchased from B.C.R.C. (No. 16704), Taiwan. The bacterium was cultured on the starch ampicillin agar plate (HiMedia, India) in a $\mathrm{CO}_{2}$-free incubator at $30^{\circ} \mathrm{C}$ for $15-18 \mathrm{~h}$ before inoculation. Fish skin model cultured for 5 days were inoculated with $\mathrm{AH}$ at $10^{3} \mathrm{CFU} / \mathrm{ml}$ in apical media and incubated at $25^{\circ} \mathrm{C}$ for $6 \mathrm{~h}$.

\section{Histological examination of the skin}

Tissue samples were rinsed with 1X phosphate-buffered saline (1X PBS) and fixed in 4\% paraformaldehyde for $24 \mathrm{~h}$. Samples were then undergone gradual dehydration with sucrose and embedded in $20 \%$ gelatin in $1 \mathrm{X}$ PBS and stored at $-80^{\circ} \mathrm{C}$. Twenty-micron thick sections were cut using a cryo-microtome (MICROM HM550, Thermo, U.S.A.), and sections were stained with either Giemsa stain (SIGMA, U.S.A.) for tissue integrity or Alcian Blue stain (ScyTek, U.S.A.) for labeling mucous cells. All the prepared slides were stored at $4^{\circ} \mathrm{C}$ for later light microscopy examination.

\section{Total RNA extraction and cDNA preparation}

RNA from the skin of $P$. hypophthalmus was extracted with the TriPure Isolation Reagent (Roche, Mannheim, Germany) following the manufacturer's instructions. The RNA pellet was dissolved in 
nuclease-free water. Extracted RNA samples were stored at $-80^{\circ} \mathrm{C}$. The reverse transcription was then performed using M-MLV Reverse transcriptase (Promega, U.S.A.) to synthesize cDNA following the manufacturer's instructions. The successful construction of cDNA library was determined by $1.5 \%$ agarose gels containing the Safeview DNA stain (GeneMark, Taipei, Taiwan).

\section{Real-Time qPCR}

The quantitative real-time PCR reaction was performed using the GoTaq qPCR Master Mix (Promega, U.S.A.) on a CFX96 real-time PCR Detection System (Bio-Rad, CA). The primers used for RT-qPCR are listed in Supplementary Table S1. The thermal cycling profile consisted of an initial denaturation at $95^{\circ} \mathrm{C}$ for $2 \mathrm{~min}$, followed by 40 cycles of denaturation at $95^{\circ} \mathrm{C}$ for $3 \mathrm{sec}$, an appropriate annealing/extension temperature at $60^{\circ} \mathrm{C}$, for $30 \mathrm{sec}$. The comparative $\mathrm{Ct}(\Delta \Delta \mathrm{Ct})$ method was used to evaluate the expression of candidate genes ${ }^{60}$. The housekeeping gene elongation factor 1-alpha (EF1- $a$ ) was used as the reference gene, and relative fold changes were calculated based on the cycle threshold (Ct) values generated by Real-Time PCR.

\section{Immunofluorescence staining}

Sections were rinsed with warm $1 \mathrm{X}$ PBS to remove gelatin and incubated with $0.2 \%$ Triton $\mathrm{X}-100$ in $1 \mathrm{X}$ PBS for $1 \mathrm{~h}$ at room temperature. The sections were then incubated with primary Claudin-1 rabbit polyclonal antibody (Invitrogen, U.S.A.) for $1 \mathrm{~h}$ and consequently incubated with cy3 conjugated goat anti-rabbit IgG secondary antibody (Abclonal, Taiwan) for $1 \mathrm{~h}$ at room temperature. All the sections were incubated with Phalloidin-Alexa Flour 488 (Invitrogen, U.S.A.) for $1 \mathrm{~h}$ and Hoechst33342 (Sigma, U.S.A.) for $20 \mathrm{~min}$ for examination of cell organization. The sections were mounted and stored in $4^{\circ} \mathrm{C}$.

Fluorescence samples were imaged using Leica DM 6000B light microscope with a SPOT Idea 5 M.P. Scientific Digital Camera System (Diagnostic Instruments Inc., Sterling Heights, MI, U.S.A.).

\section{Statistical analysis}

Statistical significance was assessed using the Student's t-test, one-way or two-way analysis of variance (ANOVA) followed by Bonferroni multiple comparisons by Prism software (GraphPad Software, La Jolla, $\mathrm{CA})$. The data are shown of more than four independent experiments.

\section{Declarations}

\section{Acknowledgments}

This study was supported by Ministry of Science and Technology grant (MOST 109-2313-B-110-002MY2). We thank Dr. Wen Zhi-Hong (National Sun Yat-Sen University) for kindly providing the fluorescent microscopy and imaging system.

\section{References}


1 Ellis, A. E. Innate host defense mechanisms of fish against viruses and bacteria. Dev Comp Immuno/25, 827-839, doi:10.1016/s0145-305x(01)00038-6 (2001).

2 Negus, V. E. The function of mucus. Acta Otolaryngo/56, 204-214, doi:10.3109/00016486309127406 (1963).

3 Harrison, G. B. et al. Studies on the role of mucus and mucosal hypersensitivity reactions during rejection of Trichostrongylus colubriformis from the intestine of immune sheep using an experimental challenge model. Int J Parasito/29, 459-468, doi:10.1016/s0020-7519(98)00221-5 (1999).

$4 \quad<$ Chapter-17--Integumentary-System_2000_The-Laboratory-Fish.pdf $>$.

5 Pan, C. Y. et al. Gene expression and localization of the epinecidin-1 antimicrobial peptide in the grouper (Epinephelus coioides), and its role in protecting fish against pathogenic infection. DNA Cell Bio/26, 403-413, doi:10.1089/dna.2006.0564 (2007).

6 Subramanian, S., Ross, N. W. \& Mackinnon, S. L. Comparison of the biochemical composition of normal epidermal mucus and extruded slime of hagfish (Myxine glutinosa L.). Fish Shellfish Immuno/25, 625-632, doi:10.1016/j.fsi.2008.08.012 (2008).

7 Lazado, C. C., Caipang, C. M. A. J. F. \& immunology, s. Mucosal immunity and probiotics in fish. 39, 78-89 (2014).

8 Zhao, F. et al. Expression profiles of toll-like receptors in channel catfish (Ictalurus punctatus) after infection with Ichthyophthirius multifiliis. Fish Shellfish Immuno/35, 993-997, doi:10.1016/j.fsi.2013.05.023 (2013).

9 Moreira, G. S., Shoemaker, C. A., Zhang, D. \& Xu, D. H. Expression of immune genes in skin of channel catfish immunized with live theronts of Ichthyophthirius multifiliis. Parasite Immuno/39, doi:10.1111/pim.12397 (2017).

10 Tongsri, P. et al. The predominant role of mucosal immunoglobulin IgT in the gills of rainbow trout (Oncorhynchus mykiss) after infection with Flavobacterium columnare. Fish Shellfish Immuno/99, 654662, doi:10.1016/j.fsi.2020.01.044 (2020).

11 Weli, S. C., Aamelfot, M., Dale, O. B., Koppang, E. O. \& Falk, K. Infectious salmon anaemia virus infection of Atlantic salmon gill epithelial cells. Virol J10, 5, doi:10.1186/1743-422X-10-5 (2013).

12 Individual variation in protein turnover and growth efficiency in rainbow trout, Oncorhynchus mykiss

(Walbaum). Proceedings of the Royal Society of London. Series B: Biological Sciences257, 141-147, doi:10.1098/rspb.1994.0107 (1997). 
13 Pritchard, C. C., Hsu, L., Delrow, J. \& Nelson, P. S. Project normal: defining normal variance in mouse gene expression. Proc Natl Acad Sci U S A98, 13266-13271, doi:10.1073/pnas.221465998 (2001).

14 Berg, G. et al. Microbiome definition re-visited: old concepts and new challenges. Microbiome8, 103, doi:10.1186/s40168-020-00875-0 (2020).

15 Mandal, R. K. et al. Temporospatial shifts within commercial laboratory mouse gut microbiota impact experimental reproducibility. BMC Bio/18, 83, doi:10.1186/s12915-020-00810-7 (2020).

16 Kelly, C. \& Salinas, I. Under Pressure: Interactions between Commensal Microbiota and the Teleost Immune System. Front Immuno/8, 559, doi:10.3389/fimmu.2017.00559 (2017).

17 Edmondson, R., Broglie, J. J., Adcock, A. F. \& Yang, L. Three-dimensional cell culture systems and their applications in drug discovery and cell-based biosensors. Assay Drug Dev Techno/12, 207-218, doi:10.1089/adt.2014.573 (2014).

18 Cano, I. et al. In vitro gill cell monolayer successfully reproduces in vivo Atlantic salmon host responses to Neoparamoeba perurans infection. Fish Shellfish Immuno/86, 287-300, doi:10.1016/j.fsi.2018.11.029 (2019).

19 Minghetti, M., Schnell, S., Chadwick, M. A., Hogstrand, C. \& Bury, N. R. J. A. t. A primary Fish Gill Cell System (FIGCS) for environmental monitoring of river waters. 154, 184-192 (2014).

20 Price, K. J. et al. Matrigel basement membrane matrix influences expression of microRNAs in cancer cell lines. Biochem Biophys Res Commun427, 343-348, doi:10.1016/j.bbrc.2012.09.059 (2012).

21 Handy, R. D., Musonda, M. M., Phillips, C. \& Falla, S. J. Mechanisms of gastrointestinal copper absorption in the African walking catfish: copper dose-effects and a novel anion-dependent pathway in the intestine. J Exp Bio/203, 2365-2377 (2000).

22 Matsumoto, R. \& Sugimoto, M. Dermal matrix proteins initiate re-epithelialization but are not sufficient for coordinated epidermal outgrowth in a new fish skin culture model. Cell Tissue Res327, 249265, doi:10.1007/s00441-006-0310-5 (2007).

23 Falk, P., Ruiz-Jasbon, F., Strigård, K., Gunnarsson, U. \& Ivarsson, M.-L. J. B. o. An ex vivo model using human peritoneum to explore mesh-tissue integration. 6, 1391-1395 (2017).

24 Gauberg, J., Wu, N., Cramp, R. L., Kelly, S. P. \& Franklin, C. E. A lethal fungal pathogen directly alters tight junction proteins in the skin of a susceptible amphibian. J Exp Bio/222, doi:10.1242/jeb.192245 (2019).

25 Srinivasan, B. et al. TEER measurement techniques for in vitro barrier model systems. J Lab Autom20, 107-126, doi:10.1177/2211068214561025 (2015). 
26 Chasiotis, H., Kolosov, D. \& Kelly, S. P. Permeability properties of the teleost gill epithelium under ion-poor conditions. Am J Physiol Regul Integr Comp Physio/302, R727-739, doi:10.1152/ajpregu.00577.2011 (2012).

27 Kolosov, D., Bui, P., Chasiotis, H. \& Kelly, S. P. Claudins in teleost fishes. Tissue Barriers1, e25391, doi:10.4161/tisb.25391 (2013).

28 Inai, T., Kobayashi, J. \& Shibata, Y. Claudin-1 contributes to the epithelial barrier function in MDCK cells. Eur J Cell Bio/78, 849-855, doi:10.1016/S0171-9335(99)80086-7 (1999).

29 Bergmann, S. et al. Claudin-1 decrease impacts epidermal barrier function in atopic dermatitis lesions dose-dependently. Sci Rep10, 2024, doi:10.1038/s41598-020-58718-9 (2020).

30 Shephard, K. L. Functions for Fish Mucus. Rev Fish Biol Fisher4, 401-429 (1994).

31 Peatman, E., Lange, M., Zhao, H. \& Beck, B. H. Physiology and immunology of mucosal barriers in catfish (Ictalurus spp.). Tissue Barriers3, e1068907, doi:10.1080/21688370.2015.1068907 (2015).

32 Patel, D. M., Bhide, K., Bhide, M., Iversen, M. H. \& Brinchmann, M. F. Proteomic and structural differences in lumpfish skin among the dorsal, caudal and ventral regions. Sci Rep9, 6990, doi:10.1038/s41598-019-43396-z (2019).

33 Olivares-Fuster, O., Bullard, S. A., McElwain, A., Llosa, M. J. \& Arias, C. R. Adhesion dynamics of Flavobacterium columnare to channel catfish Ictalurus punctatus and zebrafish Danio rerio after immersion challenge. Dis Aquat Organ96, 221-227, doi:10.3354/dao02371 (2011).

34 Zou, J. \& Secombes, C. J. J. B. The function of fish cytokines. 5, 23 (2016).

35 Schnell, S. et al. Procedures for the reconstruction, primary culture and experimental use of rainbow trout gill epithelia. Nat Protoc11, 490-498, doi:10.1038/nprot.2016.029 (2016).

36 Sonoda, S. et al. A protocol for the culture and differentiation of highly polarized human retinal pigment epithelial cells. Nat Protoc4, 662-673, doi:10.1038/nprot.2009.33 (2009).

37 Kolosov, D., Chasiotis, H. \& Kelly, S. P. Tight junction protein gene expression patterns and changes in transcript abundance during development of model fish gill epithelia. J Exp Bio/217, 1667-1681, doi:10.1242/jeb.098731 (2014).

38 Paz, A. C. et al. Challenges and opportunities for tissue-engineering polarized epithelium. Tissue Eng Part B Rev20, 56-72, doi:10.1089/ten.TEB.2013.0144 (2014).

39 Berube, K., Pitt, A., Hayden, P., Prytherch, Z. \& Job, C. Filter-well technology for advanced threedimensional cell culture: perspectives for respiratory research. Altern Lab Anim38 Suppl 1, 49-65, doi:10.1177/026119291003801S04 (2010). 
40 Dao Thi, V. L. et al. Stem cell-derived polarized hepatocytes. Nat Commun11, 1677, doi:10.1038/s41467-020-15337-2 (2020).

$41 \mathrm{Lu}, \mathrm{H}$. \& Rollman, O. Fluorescence imaging of reepithelialization from skin explant cultures on acellular dermis. Wound Repair Regen12, 575-586, doi:10.1111/j.1067-1927.2004.012510.x (2004).

42 Noguchi, M., Arifuku, I., Yamashita, A. \& Sato, K. Induction of hepatocyte growth factor and inhibition of proliferation by extracellular matrix component derived from fish skin of Reinhararditus hippoglossoides. Fisheries Sci69, 401-407, doi:DOI 10.1046/j.1444-2906.2003.00635.x (2003).

43 Hightower, L. E. \& Renfro, J. L. Recent applications of fish cell culture to biomedical research. J Exp Zoo/248, 290-302, doi:10.1002/jez.1402480307 (1988).

44 Quiniou, S. M. A., Bigler, S., Clem, L. W. \& Bly, J. E. Effects of water temperature on mucous cell distribution in channel catfish epidermis: a factor in winter saprolegniasis. Fish Shellfish Immun8, 1-11 (1998).

45 Zuchelkowski, E. M., Lantz, R. C. \& Hinton, D. E. Skin Mucous Cell Response to Acid Stress in Male and Female Brown Bullhead Catfish, Ictalurus-Nebulosus (Lesueur). Aquat Toxico/8, 139-148 (1986).

46 Fasulo, S. et al. Ectopic expression of bioactive peptides and serotonin in the sacciform gland cells of teleost skin. Arch Histol Cyto/56, 117-125, doi:10.1679/aohc.56.117 (1993).

47 Zaccone, G., Kapoor, B. G., Fasulo, S. \& Ainis, L. Structural, histochemical and functional aspects of the epidermis of fishes. Adv Mar Biol40, 253-348, doi:Doi 10.1016/S0065-2881(01)40004-6 (2001).

48 Zhang, J. et al. Toll-like receptor recognition of bacteria in fish: ligand specificity and signal pathways. Fish Shellfish Immuno/41, 380-388, doi:10.1016/j.fsi.2014.09.022 (2014).

49 Gómez, G. D., Balcázar, J. L. J. F. I. \& Microbiology, M. A review on the interactions between gut microbiota and innate immunity of fish. 52, 145-154 (2008).

50 Nikoskelainen, S., Ouwehand, A., Salminen, S. \& Bylund, G. J. A. Protection of rainbow trout (Oncorhynchus mykiss) from furunculosis by Lactobacillus rhamnosus. 198, 229-236 (2001).

51 Kanther, M. et al. Microbial Colonization Induces Dynamic Temporal and Spatial Patterns of NFkappa B Activation in the Zebrafish Digestive Tract. Gastroenterology141, 197-207, doi:10.1053/j.gastro.2011.03.042 (2011).

52 Perez, T. et al. Host-microbiota interactions within the fish intestinal ecosystem. Mucosal Immuno/3, 355-360, doi:10.1038/mi.2010.12 (2010).

53 Llewellyn, M. S., Boutin, S., Hoseinifar, S. H. \& Derome, N. Teleost microbiomes: the state of the art in their characterization, manipulation and importance in aquaculture and fisheries. Front Microbio/5, 207, 
doi:10.3389/fmicb.2014.00207 (2014).

$54 \mathrm{Li}, \mathrm{C}$. et al. Early mucosal responses in blue catfish (Ictalurus furcatus) skin to Aeromonas hydrophila infection. 34, 920-928 (2013).

55 Rakers, S. et al. 'Fish matters': the relevance of fish skin biology to investigative dermatology. Exp Dermato/19, 313-324, doi:10.1111/j.1600-0625.2009.01059.x (2010).

56 Tort, L. Stress and immune modulation in fish. Dev Comp Immuno/35, 1366-1375, doi:10.1016/j.dci.2011.07.002 (2011).

57 Small, B. C. \& Bilodeau, A. L. Effects of cortisol and stress on channel catfish (Ictalurus punctatus) pathogen susceptibility and lysozyme activity following exposure to Edwardsiella ictaluri. Gen Comp Endocrino/142, 256-262, doi:10.1016/j.ygcen.2004.12.004 (2005).

58 Pagniello, K. B., Bols, N. C. \& Lee, L. E. Effect of corticosteroids on viability and proliferation of the rainbow trout monocyte/macrophage cell line, RTS11. Fish Shellfish Immuno/13, 199-214, doi:10.1006/fsim.2001.0395 (2002).

59 Maboni, G. et al. A novel 3D skin explant model to study anaerobic bacterial infection. 7, 404 (2017).

60 Tseng, C. C. et al. Rhodoptilometrin, a Crinoid-Derived Anthraquinone, Induces Cell Regeneration by Promoting Wound Healing and Oxidative Phosphorylation in Human Gingival Fibroblast Cells. Mar Drugs17, doi:10.3390/md17030138 (2019).

\section{Figures}




\section{External}
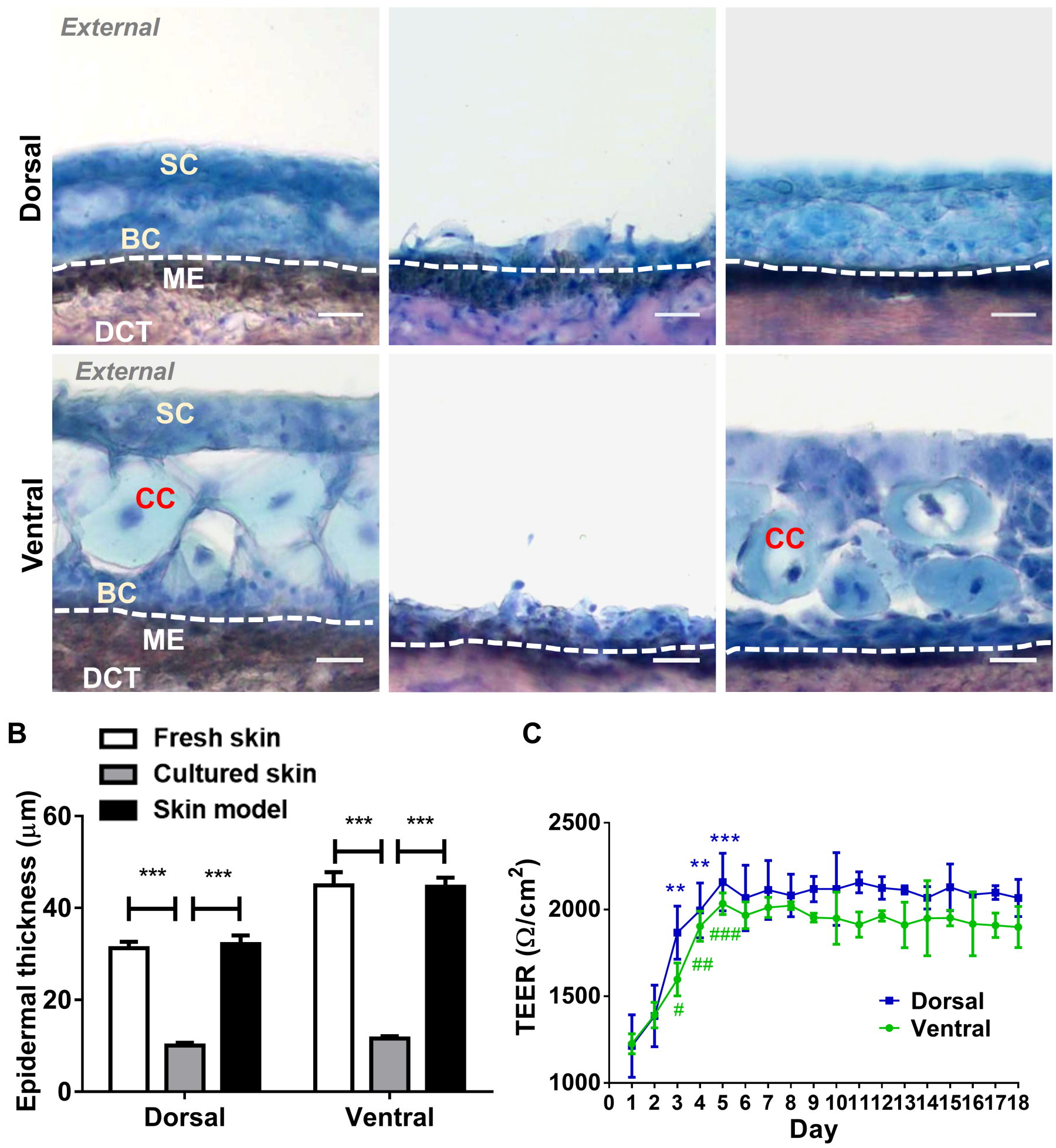

Figure 1

Morphological and functional examination of the skin model. The fresh skin, five-day cultured skin, and skin model were cryo-preserved and sectioned. (A) Tissue sections of dorsal and ventral regions skin were stained with Giemsa stain. Section showing the superficial epithelial cells (SC), basal epithelial cells (BC), melanophores (ME), dense collagenous tissue (DCT), club cells (CC). Shown are representative images, Bar $=10 \mu \mathrm{m}$. (B) Images used to determine epidermal thickness. The average evaluation values were 
determined from $>10$ randomly selected fields per sample of $4-5$ subjects in each condition. (C) The transepithelial electrical resistance (TEER) measured in fish skin model for a consecutive 18 days. The mean values of five subjects ( \pm SEM) are shown. ${ }^{* \star *} p \leq 0.001 ;{ }^{* \star} p \leq 0.01 ;{ }^{*} p \leq 0.05$ versus Dorsal group Day1; \#\#\#p $\leq 0.001 ; \# \# \mathrm{p} \leq 0.01 ; \# p \leq 0.05$ versus Ventral group Day1.

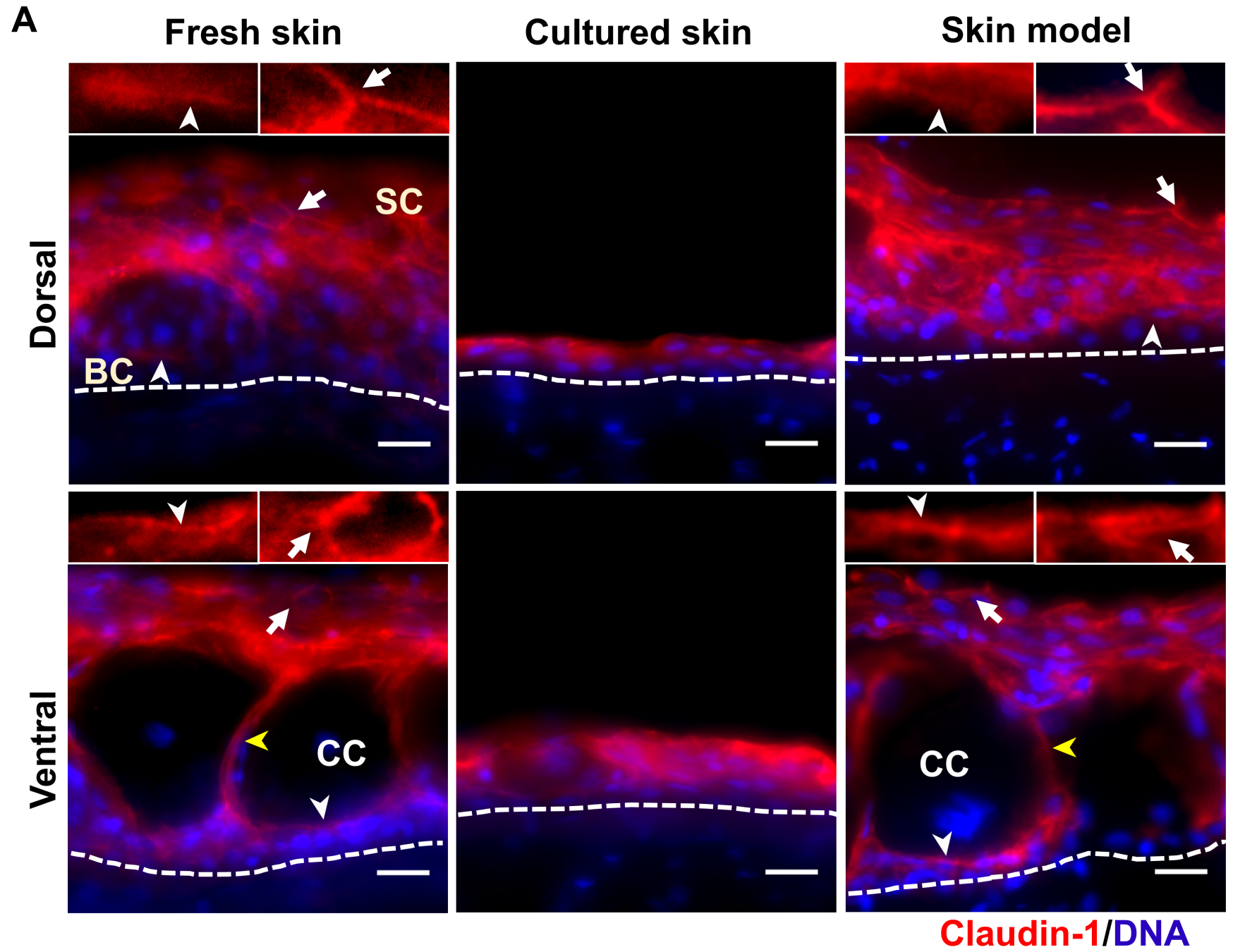

B
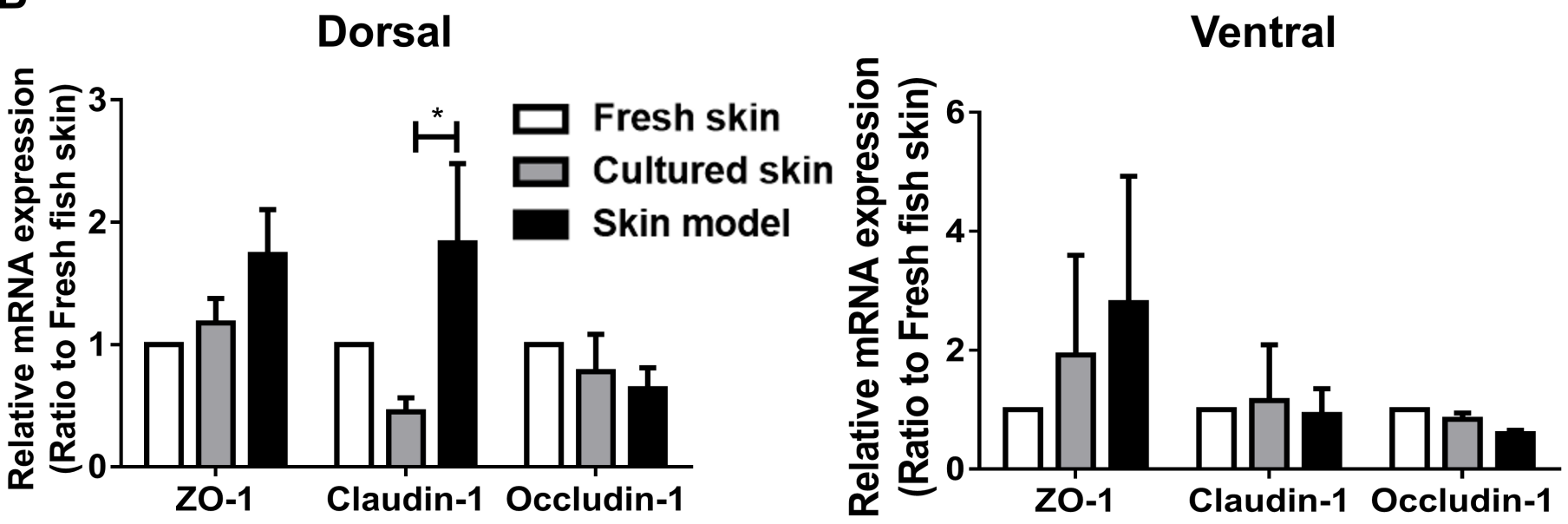

Figure 2 
Distribution and expression of tight junction proteins in the skin model. (A) Cryosections of fresh skin, five-day cultured skin, and skin model were immunostained with antibodies against Claudin-1 (red) and DNA stain (blue). Claudin-1 around superficial epithelial cells (SC), on the upper side of basal epithelial cells (BC), and around club cells (CC) was shown with white arrows, white arrowheads, and yellow arrowheads, respectively. Shown are representative images, Bar $=10 \mu \mathrm{m}$. (B) The mRNA expression level of ZO-1, Claudin-1 and Occludin-1 in cultured skin and skin model relative to the expression of the fresh skin. All data were shown as mean values ( \pm SEM) of $n=4$. ${ }^{*} \leq 0.05$

\section{A \\ Fresh skin \\ Cultured skin}

Skin model

\section{External}
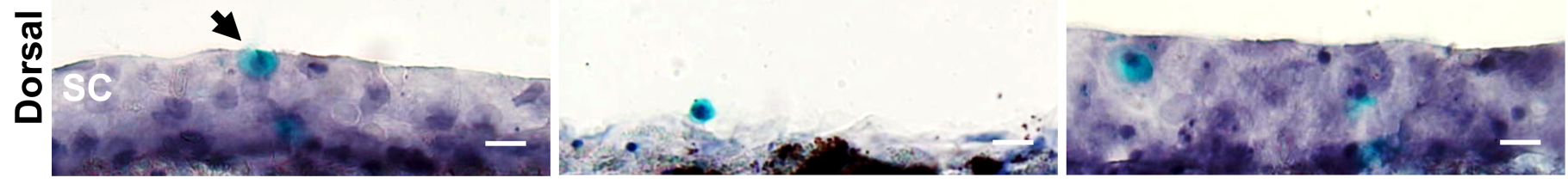

\section{External}
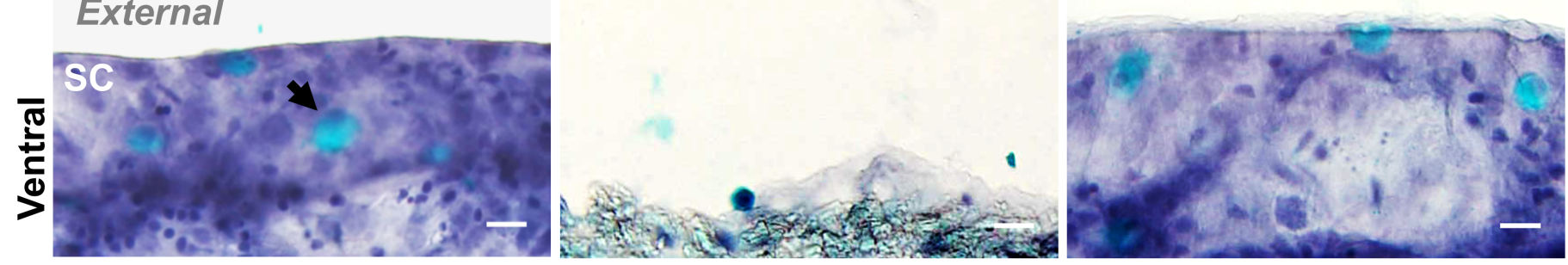

B

Fresh skin

Cultured skin

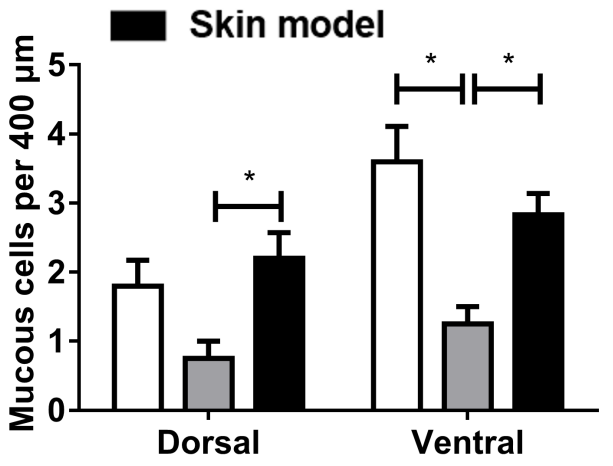

C

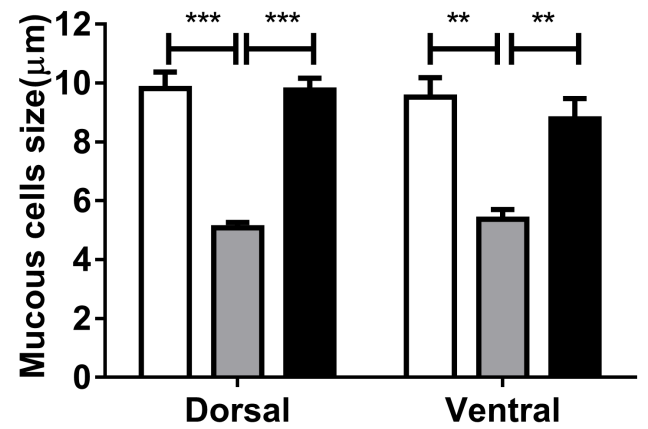

D

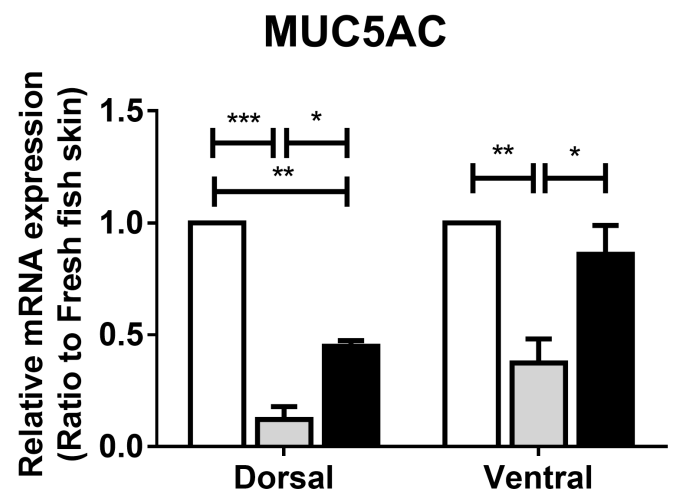

Figure 3

Morphometric analysis and mucin expression of mucous cell in the skin model. Samples from fresh skin, five-day cultured skin, and skin model were cryo-preserved and sectioned. (A) Tissue sections of dorsal and ventral regions skin were stained with Alcian blue-hematoxylin stain. Arrows point the mucous goblet cells located at superficial epithelial cell (SC) surface. Shown are representative images, Bar $=10 \mu \mathrm{m}$. Images were used to determine (B) the number and (C) average size of mucous goblet cells. (D) MUC5AC expression was measured by RT-qPCR and compared relative to the expression in fresh skin. All data were shown as mean values $( \pm$ SEM) with $n=4$ in each condition. The average values of the morphometric 
evaluation were determined from $>20$ randomly selected fields per sample of 4 subjects in each condition. ${ }^{* *} \mathrm{p} \leq 0.01 ;{ }^{*} \mathrm{p} \leq 0.05$.

A

TLR4

B
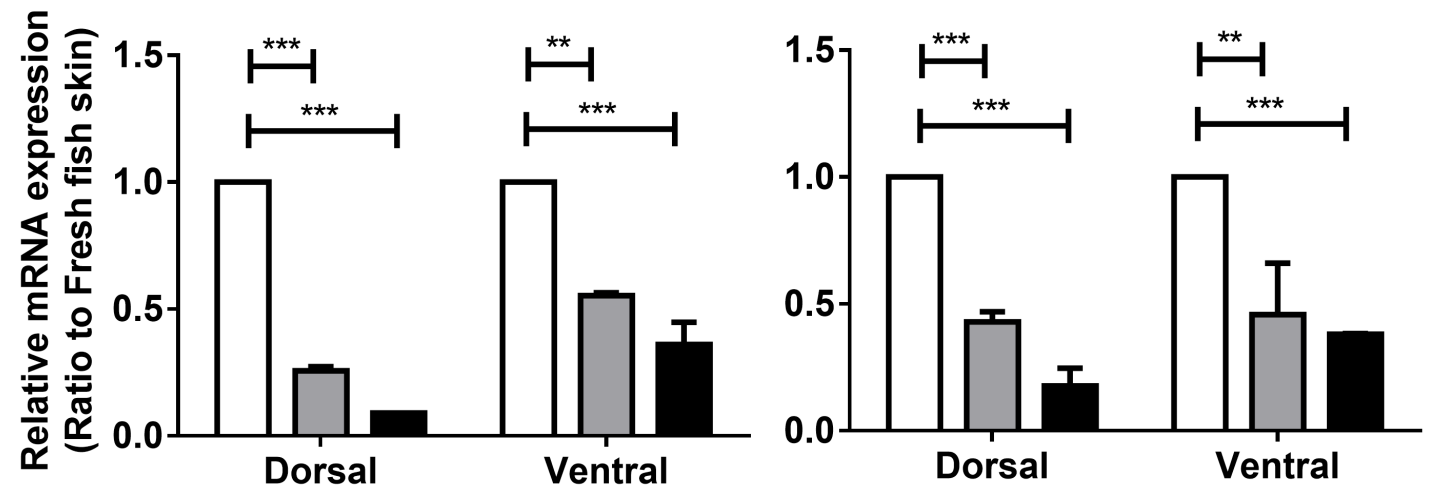

C

NF-KB

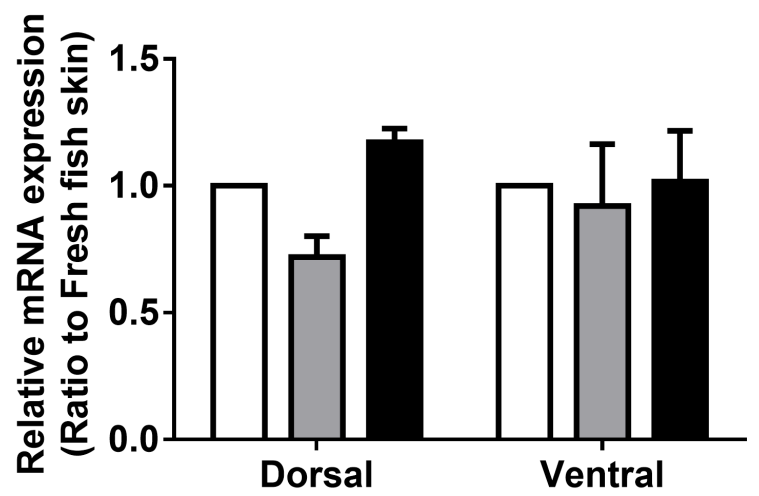

E

\section{TNFa}
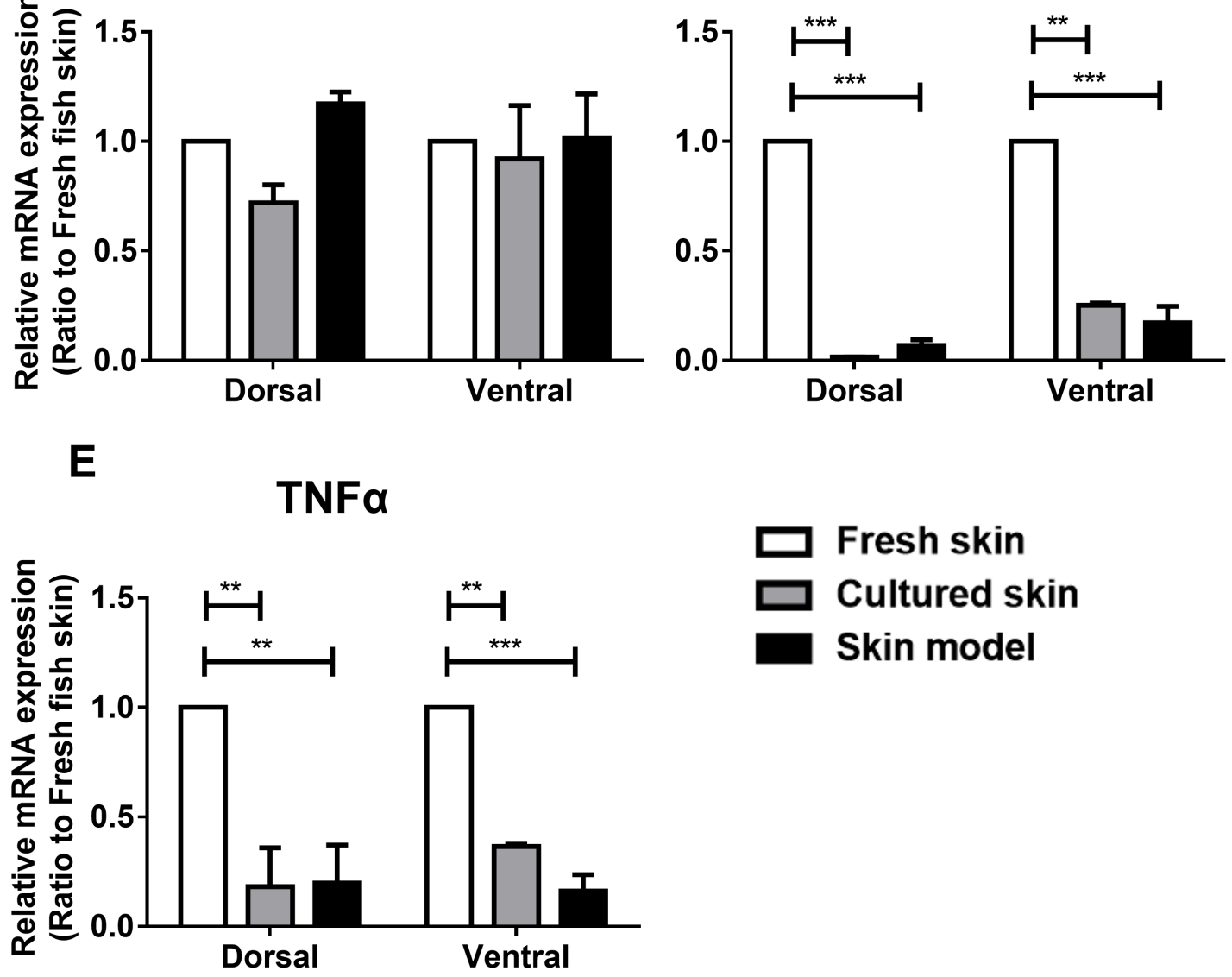
expression in fresh skin. All data were shown as mean values $( \pm S E M)$ of $n=4 . * \star * p \leq 0.001 ;{ }^{* *} p \leq 0.01$; ${ }^{*} \mathrm{p} \leq 0.05$.
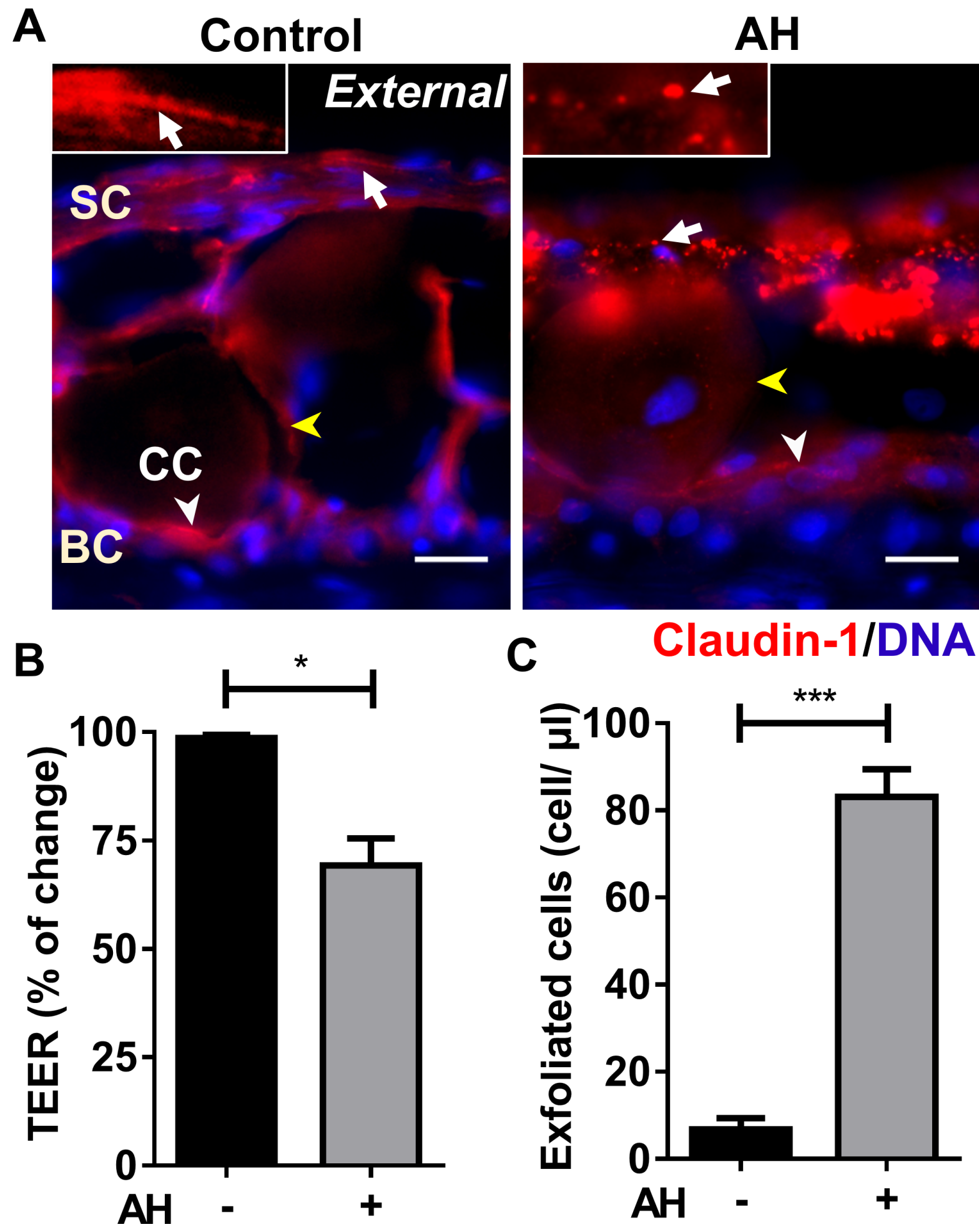

Figure 5

Redistribution of Claudin-1 and epidermis cell damage in response to $\mathrm{AH}$ inoculation in the skin model. $\mathrm{AH}$ was inoculated into the ventral skin model and incubated for $6 \mathrm{~h}$. (A) Tissue sections skin model were immunostained with antibodies against Claudin-1 (red) and DNA stain (blue). Claudin-1 around 
superficial epithelial cells (SC), on the upper side of basal epithelial cells (BC), and around club cells (CC) was shown with white arrows, white arrowheads, and yellow arrowheads, respectively. Shown are representative images, Bar $=10 \mu \mathrm{m}$. (B) The transepithelial electrical resistance (TEER) was measured. (C) Exfoliated cells in the apical chamber were counted using light microscopy. All data were shown as mean values $\left( \pm\right.$ SEM) of $n=5$. ${ }^{* *} p \leq 0.001 ;{ }^{* *} p \leq 0.01 ;{ }^{*} p \leq 0.05$.

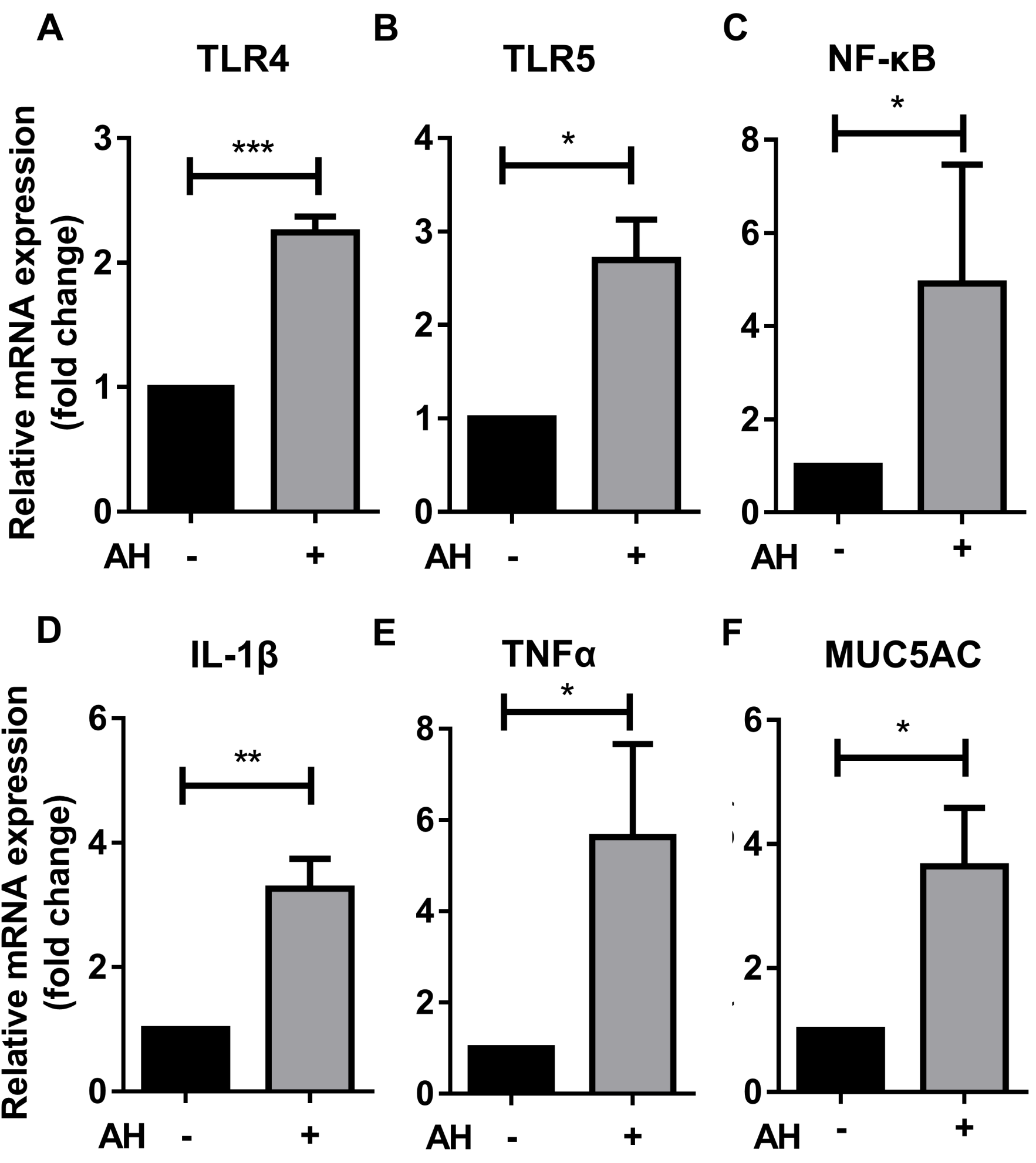

Figure 6 
Effect of $\mathrm{AH}$ inoculation on innate immune marker expression in the fish skin model. The ventral skin model was inoculated with AH and incubated for $6 \mathrm{~h}$. The RNA was extracted and followed by RT-qPCR for measuring expression. The expression of (A) TLR4, (B) TLR5, (C) NF-KB, (D) IL-1B, (E) TNFa, (F) MUC5AC in AH inoculated skin model were compared to expression in the no bacteria control assigned a value of 1 . All data are shown as mean values $\left( \pm\right.$ SEM) of $n=5$. ${ }^{* \star} p \leq 0.001 ;{ }^{*} p \leq 0.01 ;{ }^{\star} p \leq 0.05$.

\section{Supplementary Files}

This is a list of supplementary files associated with this preprint. Click to download.

- Supplementaryinformation.docx

- FigureS1.zip

- TableS1.docx

- Figures2.zip 